\title{
Dandruff-associated smouldering alopecia: a chronobiological assessment over 5 years
}

\author{
C. Piérard-Franchimont, E. Xhauflaire-Uhoda, G. Loussouarn,* D. Saint Léger* and G. E. Piérard \\ Department of Dermatopathology, University Hospital Sart Tilman, Liège, Belgium; and 'L'Oréal Recherche, Clichy, France
}

\section{Summary}

\begin{abstract}
Background. In some individuals, dandruff may be recurrent and even chronic. This represents a difficult-to-treat condition. Excessive hair shedding and diffuse alopecia may develop.
\end{abstract}

Objectives. To evaluate the chronobiological aspects of dandruff, hair shedding and alopecia.

Methods. This study was performed in eight men suffering from such a scalp condition. They were examined 40 times at regular intervals for five consecutive years. Hair-density assessments and trichograms were performed at least twice per trimester on the parietal region of the scalp, corresponding to an area where dandruff was present.

Results. A positive correlation was found between the percentage of telogen hairs and dandruff severity as assessed by the squamometry index. Bimodal yearly biorhythms were found for dandruff severity, telogen counts and hair loss between two consecutive visits. The chronobiological fluctuations were prominent in some study participants, but remained inconspicuous in others. The biorhythms were almost synchronized in all participants, showing variations over the year.

Conclusions. The biorhythms on the hair cycle in dandruff are not fundamentally different from those previously reported in subjects without dandruff. The periodicity may be an intrinsic feature of human skin.

It is well documented that the main exogenous triggering factor in dandruff and seborrhoeic dermatitis is yeasts of the genus Malassezia. ${ }^{1-6}$ Numerous open and double-blind placebo-controlled studies have demonstrated the clinical efficacy of some antifungals. ${ }^{3,4,6}$ However, in some instances, dandruff relapses are so frequent that the disorder follows a chronic course. Dandruff is associated with discrete subclinical inflammation, possibly in response to the presence of the yeasts $^{7,8}$ and other triggering factors. As microinflammation may trigger pruritus, perturbations in the hair cycle, hair shedding and alopecia may result. ${ }^{7-10}$

This study was undertaken over 5 years in subjects prone to chronic dandruff partly resistant to ketocon-

Correspondence: Professor G. E. Piérard, MD, PhD, Department of Dermatopathology, CHU Sart Tilman, B-4000 Liège, Belgium.

E-mail: gerald.pierard@ulg.ac.be

Conflict of interest: none declared.

Accepted for publication 28 June 2005 azole shampoo. Chronobiological aspects of dandruff, hair shedding and alopecia were evaluated.

\section{Patients and methods}

This open, single-centre, outpatient study was conducted in accordance with the Declaration of Helsinki, and the protocol was reviewed by the local ethics committee.

Eight men, aged from 21 to 29 years, were enrolled and completed this study. They were university scientists seeking for advice in an attempt to control chronic dandruff associated with a mild itchy and diffuse alopecia. They had used several different brands of antidandruff shampoos over the years. Transient benefit had been most frequently observed, but dandruff tended to recur 1-3 weeks after stopping the particular shampoo. During the 5-year follow-up, the volunteers used antidandruff and mild shampoos freely and alternately, according to their current scalp condition. A 3-day interval was always observed between the last shampoo 
and the visit for laboratory examination. At each visit, three evaluations were performed: squamometry $\mathrm{X}$, hair-density determination and trichogram.

Squamometry $\mathrm{X}$ was used as previously described ${ }^{2,11}$ to assess scalp scaliness, using the self-adhesive clear disc method. ${ }^{11}$ Corneodiscs (L’Oréal, Paris, France) were applied to the scalp under controlled pressure $\left(110 \mathrm{~g} / \mathrm{cm}^{2}\right)$. The harvested material was stained for 1 min using a a $30 \%$ in ethanol solution of toluidine blue and basic fuschin. Squamometry index (SQI) was given by the Chroma $\mathrm{C}^{*}$ value as measured by reflectance colourimetry (Chroma Meter ${ }^{\circledR}$ CR200; Minolta, Osaka, Japan). The collected material was also observed under the microscope in order to assess the number of yeasts attached to the scales.

Hair density $\left(\mathrm{N} / \mathrm{cm}^{2}\right)$ was evaluated from photographs taken using a Dermaphot ${ }^{\circledR}$ (Heine Delta 10, Pabish, Germany) on a clipped scalp area repositioned over time using a three-point template. ${ }^{10}$ Differences in hair density $(\Delta \mathrm{n})$ were calculated between two successive visits. A trichogram was also collected in order to derive the percentage of telogen $(\mathrm{T})$ hairs. In each case, about 60-90 hairs were grasped with a rubber-armed clip and pulled out firmly in order to obtain the whole hairs with roots. ${ }^{10}$ During the 2 last years of observation, two groups of telogen hairs were distinguished according to the presence (covered T) or the absence (uncovered T) of an epithelial sac appended at the bottom of each hair (Fig. 1). Those removed with the epithelial sheath were considered to be in early telogen stage and those without the epithelial sheath were considered to be close to natural shedding at teloptosis. ${ }^{12}$

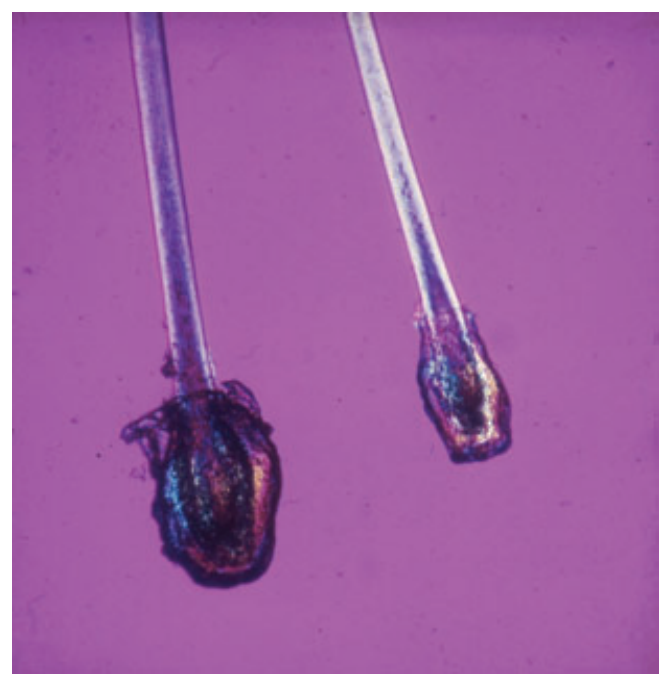

Figure 1 Aspect of telogen hairs with (covered T) and without (uncovered T) an epithelial sac, suggesting early and late telogen phase, respectively.

\section{Statistical analysis}

Correlations were investigated using the Spearman test. The period of the year when data were collected was also taken into account. For that purpose, rhythm consistency was verified in each subject before plexograms cumulating data over a period of 12 months were created. ANOVA and t-test analysis were performed in order to disclose any annual biorhythm. A $P$-value $<0.05$ was considered statistically significant.

\section{Results}

The microscopic examination of dandruff revealed the presence of yeasts of the genus Malassezia, ranging in number from about 110 to 470 per $0.1 \mathrm{~mm}^{2}$ of scales. Their density in the harvested material varied widely. No obvious variation in the overall yeast density was seen over the year.

Dandruff severity as assessed by SQI was positively correlated $(r=0.53)$ with $\mathrm{T}$ level (Fig. 2a). Data gathered over the latter 2 years of the study (16 evaluations per volunteer) suggested that the proportion of covered $\mathrm{T}$ remained quite constant (4-6\%) over time, with little, if any, correlation with dandruff severity. By contrast, uncovered $\mathrm{T}$ increased with dandruff severity as shown by SQI $(r=0.66)$. No correlation was found between SQI and hair density $(r=0.02)$ or between SQI and $\Delta \mathrm{n}(r=-0.04)$ (Figs 2b, c).

Cyclic variations in the mean monthly values of SQI, $\mathrm{T}$ and $\Delta \mathrm{n}$ were found over a 12-month period. Dandruff condition, as assessed by the mean monthly value of SQI, was most severe in April and September, and least severe in July (Fig. 2d). This biorhythm was consistent over the 5 years and synchronized in six of the eight participants, remaining inconspicuous in the other two. The proportion of hairs in the resting phase as assessed by the mean monthly $T$ value was higher in September and December, and lower in June (Fig. 3a). This $\mathrm{T}$ biorhythm was consistent and synchronized in all subjects. Hair density as assessed by the mean monthly $\mathrm{N}$ value did not show any significant cyclic variations (Fig. 3b). By contrast, the most recent change in hair density between two successive visits (mean monthly $\Delta \mathrm{n}$ ) exhibited prominent changes over the year in five of eight subjects. The loss of hair was more prominent in October, November and January (Fig. 3c).

\section{Discussion}

Chronobiology is an important but often neglected aspect in the pilosebaceous apparatus and scalp physiopathol- 
(a)

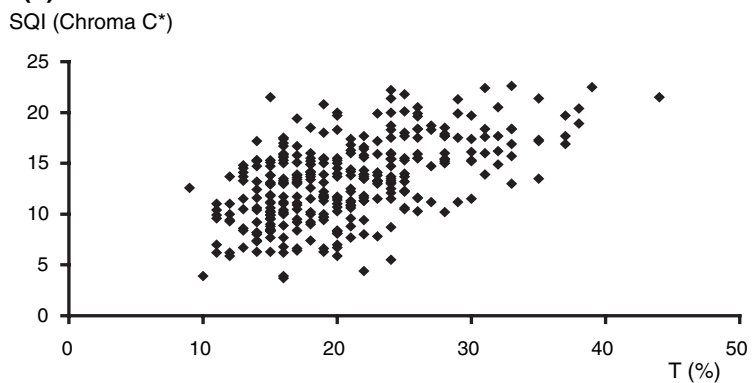

(b)

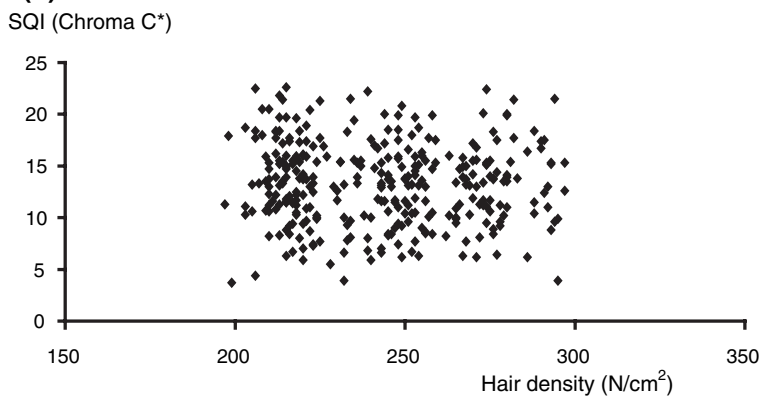

(c)

SQI Chroma C*

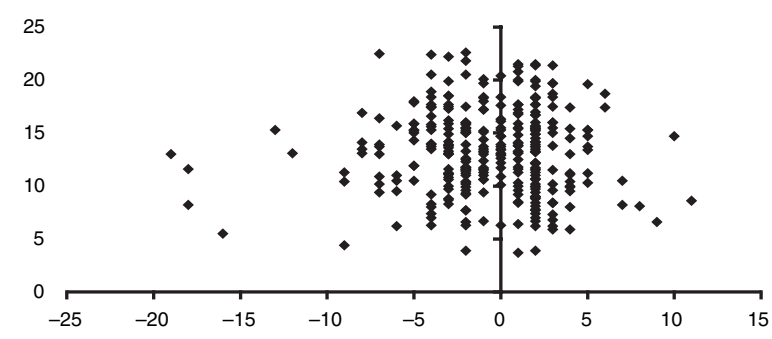

(d)

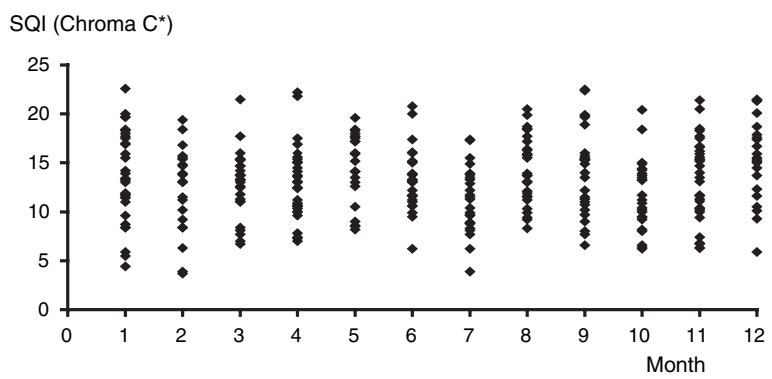

Figure 2 Scatterplot of (a) the correlation $(r=0.53)$ between the squamometry index (SQI) of dandruff severity and the percentage (\%) of telogen hairs (T); (b) values of the squamometry index (SQI) and the hair density $\left(\mathrm{N} / \mathrm{cm}^{2}\right)$ (no correlation was seen); (c) values of the squamometry index (SQI) and the difference in hair density $/ \mathrm{cm}^{2}(\Delta \mathrm{n})$ between two successive visits (no correlation was seen); (d) yearly biorhythm in dandruff severity as assessed by the squamometry index (SQI). (a)

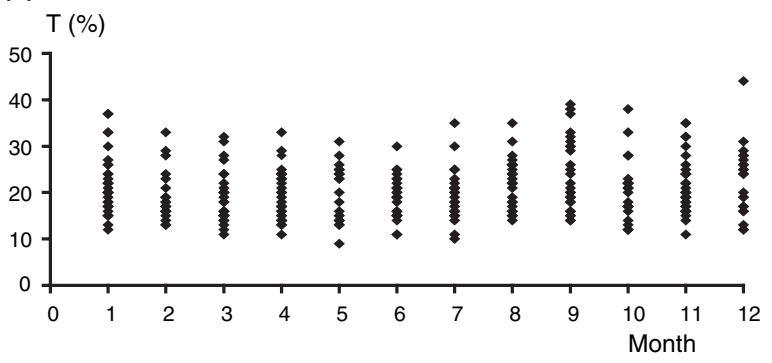

(b)

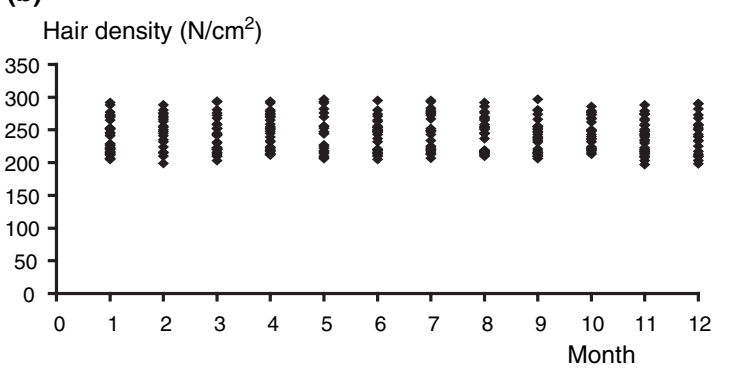

(c)

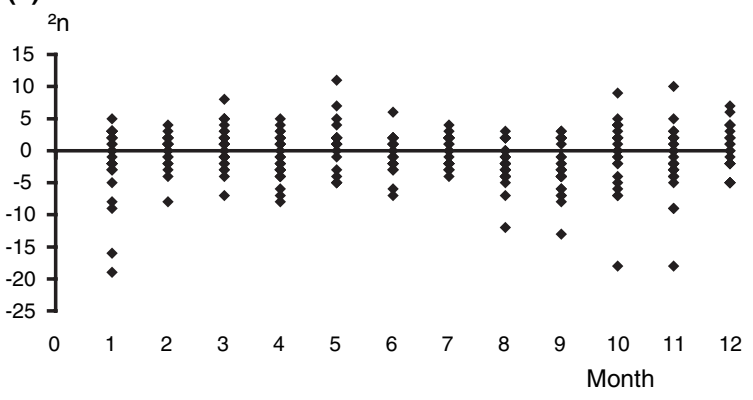

Figure 3 (a) Yearly biorhythm in telogen counts (T). (b) Absence of clear-cut yearly variation in hair density $\left(\mathrm{N} / \mathrm{cm}^{2}\right)$. (c) Yearly biorhythm of the difference in hair density $/ \mathrm{cm}^{2}(\Delta \mathrm{n})$ between two successive visits.

ogy. ${ }^{13-20}$ In this study, we found yearly cycles in dandruff condition, with evidence of biorythms over the course of 1 year in dandruff severity (SQI), telogen counts (T) and recent hair shedding $(\Delta \mathrm{n})$. There was also a correlation between telogen counts and dandruff severity.

Pulling out hair during the sampling procedure for trichogram requires exerting a traction force. The collected material reveals the location of the weakest binding sites in the hair follicle apparatus. Telogen hair lost in normal daily life never exhibited an epithelial sac attached to the bottom. This indicates that at teloptosis, hair binding to the epithelial sheath is weak. By contrast, telogen hair with an attached epithelial sac found in a trichogram indicates that binding forces between the epithelial sheath and the surrounding dermis remain strong. At this stage, telogen hair is still firmly attached to the scalp and is 
Dandruff-associated smouldering alopecia: a chronobiological assessment over 5 years $\bullet$ C. Piérard-Franchimont et al.

presumably not close to teloptosis. In this study, hairs in early telogen seemed little affected by dandruff process, whereas hairs in late telogen stage, preceding teloptosis, increased with dandruff severity. This finding may be interpreted as synchronized premature teloptosis, which is often accompanied by or shortly precedes increased hair shedding. ${ }^{10,12}$ This evolution may be the origin of diffuse alopecia. ${ }^{7,8}$ It may be further aggravated by retardation of anagen hair growth ${ }^{16,17,21,22}$ corresponding to the hair eclipse phenomenon. ${ }^{23}$

Whether or not the altered desquamation process in dandruff is similar or linked to the altered anchorage of telogen hairs to the follicle is unknown. These processes are highly complex, as they take place within a multistep procedure involving a series of enzyme activities. ${ }^{24,25}$

In this study, dandruff severity followed a bimodal pattern with the acrophases in April and September. The spring episode seemed to have no perceptible influence on the hair cycle and hair shedding. By contrast, dandruff occurring in late summer was associated with increased telogen counts and was followed by increased hair loss during the fall season. A second peak of increased telogen counts was found at the end of winter, followed by increased hair shedding.

The presently reported biorhythms on the hair cycle in dandruff are not fundamentally different from those previously reported in subjects without dandruff. ${ }^{14,17,18}$ The biological origin of dandruff remains unclear. The periodicity may be an intrinsic feature of human skin, thus the Malassezia load may not abolish or considerably alter scalp chronobiology.

\section{References}

1 Hay RJ, Graham-Brown RA. Dandruff and seborrhoeic dermatitis; causes and management. Clin Exp Dermatol 1997; 22: 3-6.

2 Piérard-Franchimont C, Arrese JE, Durupt G, Ries G, Cauwenbergh G, Piérard GE. Correlation between Malassezia spp. load and dandruff severity. J Mycol Med 1998; 8: 83-6.

3 Baroni A, De Rosa R, De Rosa A, Donnarumma G, Catalonotti P. New strategies in dandruff treatment: growth control of Malassezia ovalis. Dermatology 2000; 201: 146-7.

4 Piérard-Franchimont C, Hermanns JF, Degreef H, Piérard GE. From axioms to new insights into dandruff. Dermatology 2000; 200: 93-8.

5 Piérard GE. Seborrheic dermatitis today, gone tomorrow ? The link between the biocene and treatment. Dermatology 2003; 206: 187-8.

6 Gupta AK, Madzia SE, Batra R. Etiology and management of seborrheic dermatitis. Dermatology 2004; 208: 89-93.

7 Piérard-Franchimont C, De Doncker P, Wallace R, Cauwenbergh G, Piérard GE. Ketoconazole shampoo: effect of long term use in androgenic alopecia. Dermatology 1998; 196: $474-7$.

8 Piérard-Franchimont C, Goffin V, Henry F, Uhoda I, Braham C, Piérard GE. Nudging hair shedding by antidandruff shampoos. A comparison of $1 \%$ ketoconazole, $1 \%$ piroctone olamine and 1\% zinc pyrithione formulations. Int J Cosmet Sci 2002; 24: 254-6.

9 Piérard GE, Piérard-Frachimont C, Nikkels-Tassoudji N, Nikkels AF, Saint Léger D. Improvement in the inflammatory aspect of androgenetic alopecia. A pilot study with an antimicrobial lotion. J Dermatol Treat 1996; 7: 153-7.

10 Piérard GE, Piérard-Franchimont C, Marks R, Elsner P. EEMCO guidance for the assessment of hair shedding and alopecia. Skin Pharmacol Physiol 2004; 17: 98-110.

11 Piérard-Franchimont C, Henry F, Piérard GE. The SACD method and the XLRS squamometry tests revisited. Int J Cosmet Sci 2000; 22: 437-46.

12 Piérard-Frachimont C, Piérard GE. Teloptosis, a turning point in hair shedding biorhythms. Dermatology 2001; 203: 115-17.

13 Piérard-Franchimont C, Piérard GE, Kligman A. Seasonal modulation of the sebum excretion. Dermatologica 1990; 181: 21-2.

14 Randall VA, Ebling FJG. Seasonal changes in human hair growth. Br J Dermatol 1991; 124: 146-51.

15 Verschoore M, Poncet M, Krebs B, Ortonne JP. Circadian variations in the number of actively secreting sebaceous follicles and anrogen circadian rhythms. Chronobiol Int 1993; 10: 349-59.

16 Courtois M, Loussouarn G, Hourseau C, Grollier JE. Hair cycle and alopecia. Skin Pharmacol 1994; 7: 84-9.

17 Courtois M, Loussouarn G, Hourseau S, Grollier JF. Periodicity in the growth and shedding of hair. Br J Dermatol 1996; 134: 47-54.

18 Piérard GE, Piérard-Franchimont C. L'effluvium télogène actinique: une facette de la chronobiologie humaine. Int $J$ Cosmet Sci 1999; 21: 15-21.

19 Henry F, Arrese JE, Claessens N, Piérard-Franchimont C, Piérard GE. La peau et son horloge chronobiologique au quotidien. Rev Med Liège 2002; 57: 661-5.

20 Piérard-Franchimont C, Henry F, Loussouarn G, et al. Chronophysiologie circadienne du cuir chevelu. Pathol Biol, in press.

21 Guarrera M, Rebora A. Anagen hairs may fail to replace telogen hairs in early androgenetic alopecia. Dermatology 1996; 192: 2831.

22 Guarrera M, Cipriani C, Rebora A. Delayed telogen replacement in a boy's scalp. Dermatology 1998; 197: 335-7.

23 Piérard-Frachimont C, Petit L, Loussouarn G, Saint Léger D, Piérard GE. The hair eclipse phenomenon. Sharpening the focus on the hair cycle chronobiology. Int J Cosmet Sci 2003; 25: 295-9.

24 Piérard GE, Goffin V, Hermanns-Lê T, Piérard-Franchimont C. Corneocyte desquamation. Int J Mol Med 2000; 6: 217-21.

25 Rawlings AV. Trends in stratum corneum research and the management of dry skin conditions. Int J Cosmet Sci 2003; 25: 63-95. 